\title{
The New Principle-Practice Gap: The Disconnect between Diversity Beliefs and Actions in the Workplace
}

Jamillah Bowman Williams

Georgetown University Law Center, jamillah.williams@law.georgetown.edu

Jonathan Cox

University of Central Florida - Department of Sociology, jonathan.cox@ucf.edu

This paper can be downloaded free of charge from:

https://scholarship.law.georgetown.edu/facpub/2309

https://ssrn.com/abstract=3707104

Forthcoming in Sociology of Race and Ethnicity.

Presented at the American Sociological Association Annual Meeting, August 2020.

This open-access article is brought to you by the Georgetown Law Library. Posted with permission of the author. Follow this and additional works at: https://scholarship.law.georgetown.edu/facpub

Part of the Civil Rights and Discrimination Commons, Labor and Employment Law Commons, and the Law and Race Commons 


\title{
The New Principle-Practice Gap:
}

\section{The Disconnect between Diversity Beliefs and Actions in the Workplace}

KEYWORDS: diversity ideology, racial attitudes, work, discrimination, racism

WORD COUNT: 8,898

\begin{abstract}
Following increased calls for racial justice, many organizations have pledged to play their part in dismantling systemic racism. One common step leaders take is to invest in diversity and inclusion programs. Yet, despite organizations' bold claims to value diversity and the investment of billions of dollars on related efforts, workplace discrimination continues to be a major factor in the lives of people of color. Additionally, existing research highlights a principle-policy gap, wherein people--particularly White Americans--espouse support for the principles of diversity, yet their support wanes for policies that address inequalities. In this survey study, we explore attitudes about organizational diversity efforts and further examine how these beliefs shape workplace decision-making. Our analysis of open-ended responses reveals a major disconnect, where individuals say diversity is important in principle, yet in practice do not take actions to further the goals of diversity and inclusion programs, a phenomenon we label the "principle-practice gap." We use diversity ideology as the theoretical link to help explain why this subtle resistance to action might occur. We find that the principle-practice gap is more pronounced for those who view diversity as important because it improves outcomes. Conversely, those who think diversity is an important goal because of workplace inequality are more likely to take action, such as promoting a Black man. These findings help reveal which people endorsing diversity in principle are more likely to take action and which tend to be more performative and less connected to practices that counter structural inequality.
\end{abstract}




\section{The New Principle-Practice Gap: The Disconnect between Diversity Beliefs and Actions in the Workplace}

A recent study estimates that 98 percent of companies in the United States have some type of diversity program in place (Boston Consulting Group 2019). These may include outreach to recruit and hire more women and racial and ethnic minorities, training programs to raise awareness of bias, talent development programs to make sure these candidates are growing professionally, and affinity groups that emphasize improving workplace culture (Dobbin 2009; Edelman, Fuller, and Mara-Drita 2001; Kalev, Dobbin, and Kelly 2006). In principle, many individuals seem to agree with these efforts. In a nationally representative survey of working adults, 84 percent of White respondents stated that they think it is important to strive for diversity in the workplace (Williams 2018a). In response to recent mass protests and calls for racial justice, White Americans in particular claim they are now more conscious of systemic and structural racism, as reflected by a recent New York Times headline: "White Americans Say They Are Waking Up to Racism. What Will It Add Up To?” (Harmon and Burch 2020). This headline conveys an important question, however: does being "woke" enough to express support for diversity initiatives mean that actions will match these beliefs? Further, how do non-Whites fit into this equation?

Despite color-blind ideals in the U.S., striking racial inequality persists in the workplace (Pager and Shepherd 2008; Stainback and Tomaskovic-Devey 2012). Looking specifically at hiring practices, there is substantial evidence of racial disparities. For instance, employers often overlook resumes with ethnic sounding names (Bertrand and Mullainathan 2004). Black applicants are half as likely as equally qualified Whites to receive a callback or job offer (Pager, Western, and Bonikowski 2009). Whites also benefit from same-race referrals, while Blacks only benefit from referrals when the referring employee is White, and the evaluator is low in prejudice 
(Bonilla-Silva 2018a). Further, Blacks and Latino/as with no criminal record fare no better than, or are even less likely to be hired, than Whites just released from prison (Agan and Starr 2016; Pager 2003; Pager et al. 2009). Black candidates who suppress their racial identity by "whitening" their resumes are extended greater opportunities (Kang et al. 2016). Even once Black Americans are hired into the workforce, discrimination persists. For example, a recent randomized experiment found that identical legal memos were given lower ratings and noted for more errors when thought to be written by a Black rather than a White attorney (Reeves 2013).

While many organizations claim to value diversity and invest billions of dollars in related programming to increase diversity and inclusion, there is a lack of systematic empirical research on what diversity means to people, the narratives individuals use to describe its role in organizations, and how these beliefs may influence behavior. Critical diversity scholars, however, have investigated diversity as both discourse and as an ideology. Diversity as a discourse focuses on the language of diversity, wherein diversity is often framed as "happy talk," or a celebration of difference (Bell and Hartmann 2007; Berrey 2015) that can be leveraged both in support of or as opposition to diversity efforts, and rarely leads to significant structural change. Diversity as ideology, on the other hand, highlights the ways in which diversity is a shared logic that perpetuates and maintains the racial status quo and White dominance, especially in multiracial spaces (Embrick 2011; Mayorga-Gallo 2014; Smith and Mayorga-Gallo 2017). More than just a way of speaking about diversity, diversity ideology provides the logical tools by which individuals and organizations can present themselves as supporters of equity and inclusivity, without making any changes in behaviors and policies that result in lasting, impactful changes for people of color in the workplace (Embrick 2011). Understanding diversity as an ideology helps uncover the ways in which actions (or inactions) are justified. 
This project is guided by three overarching research questions. First, to what extent do people believe it is important for organizations to strive for workplace diversity, and how do they explain their views regarding diversity? Second, how do they explain their views regarding why organizational diversity is important? Third, how do these attitudes about workplace diversity influence individual employment decisions? We use a survey study to explore these guiding research questions, analyzing participants' responses to open-ended questions as well as their decisions in response to a vignette involving a Black man being considered for a promotion after being initially overlooked. Our analysis revealed that many of the 311 research participants say they think workplace diversity is important, but few take action to promote the Black man, a phenomenon we identify as the principle-practice gap.

A careful examination of the participants' open-ended responses about why they believe organizational diversity is important reveals that some participants believe diversity is important because it leads to better outcomes in organizations, some think diversity is important because of existing inequalities (or past discrimination), and others more vaguely believe it is important because of shifting demographics. These views vary by race and gender, and the respondents who acknowledge racism and other forms of inequality are the most likely to take action. Our

analysis reveals that when individuals support diversity because it is a rational means to a desired end (e.g., improved business outcomes), they express notions consistent with diversity ideology, which they may use to rationalize their inaction and maintain the status quo.

\section{WORKPLACE DIVERSITY BELIEFS}

As a result of contemporary conceptualizations of racism, we have generally seen a shift in the racial attitudes of White Americans away from overt prejudice towards more egalitarian 
beliefs about race (Bonilla-Silva 2018a; Sears and Henry 2005). Compared to the past, White Americans now overwhelmingly support principles of equality such as open housing and equal access to jobs (Krysan and Moberg 2016). More employers are also investing in diversity initiatives to lessen inequality, improve unity, and comply with civil rights laws (Dobbin 2009; Edelman et al. 2001; Kalev et al. 2006).

Unfortunately, however, social scientists have uncovered inconsistencies in White American attitudes towards race. While White Americans express broad support for racial equality in principle, they often oppose specific policies like race-conscious diversity programs that address racial inequalities, a concept known as the principle-policy gap (Smith and MayoraGallo 2017; Taylor and Parcel 2019). The principle-policy gap is fueled in part by color-blind racism, wherein Whites fail to see existing racial inequalities as the result of historical discrimination and racism (Mayrl and Saperstein 2013).

This is consistent with research finding that, compared to other groups, Whites generally view organizations as fairer and more inclusive of women and racial and ethnic minorities than other groups (Mor Barak et al. 1998). Black Americans view organizations the least favorably on these grounds (Miller and Kaiser 2001). For Whites in particular, the proliferation of diversity programs may lead to the false impression that Black employees are prized by organizations and thus face no discriminatory barriers. As such, Whites may not be swayed by organizational interventions aimed to improve diversity and inclusion. They may see these measures as unneeded, or even inherently unfair and biased against White people, whom they believe to be the true targets of discrimination (Dover, Major, and Kaiser 2016; Norton and Sommers 2011).

Historically, Whites have also favored individualistic explanations for racial and ethnic socioeconomic gaps, over less popular "system challenging" structuralist beliefs that 
acknowledge racism and discrimination (Hunt 2007: 392). Contemporary White explanations for these inequalities, such as hiring, promotion, and pay gaps, tend to be based not on traditional notions of individualism (or racism, i.e., a "belief in the innate or genetic inferiority of Blacks"), but instead on "motivational individualism," which attributes Black-White inequalities to Blacks' supposed lack of will or effort (Hunt 2007: 392). Thus, even when Whites say they support equality in principle, diversity efforts may be inconsistent with their views that organizations are fair and equitable, and that any inequality is a product of low effort on the part of racial and ethnic minorities.

On the other hand, racially and ethnically minoritized people assign more value to and feel more comfortable with diversity and related efforts than Whites (Danbold and Unzueta 2019; Mor Barak et al. 1998). For example, compared to White men, White women and women and men of color place greater value on employer efforts to promote diversity, and hold more favorable attitudes about the qualifications of women and non-White minorities (Kossek \& Zonia 1993). A cross-sectional survey and case study of public sector employees and managers also found that women and racial minorities consistently express stronger support for workplace diversity and diversity management initiatives, compared to their male counterparts (Soni 2000).

\section{DIVERSITY IDEOLOGY}

Sociologist David G. Embrick (2011) first posited the concept of diversity ideology to explain the disconnect between the purpose and outcomes of corporate diversity policies. According to Embrick (2011: 544), corporations "systematically and strategically co-opted the notions of diversity that were established by the civil rights movement and helped to perpetuate a diversity ideology that has enabled them to advocate racial and gender equality yet maintain 
highly inequitable work environments and an even more inequitable chain of command." For instance, under the guise of diversity ideology, corporations pushed for increased diversity at middle and lower tiers, but little to no change was demonstrated at higher levels, like upper management, CEOs, and other C-suite positions (Smith and Mayorga-Gallo 2017).

Diversity ideology works as a sort of racial logic that maintains White supremacy and dominance, especially in multiracial spaces, through four tenets: diversity as acceptance, diversity as intent, diversity as commodity, and diversity as liability (Mayorga-Gallo 2019). Diversity as acceptance is the tenet that diversity scholars identify most often, wherein diversity is characterized by the tolerance and acceptance of a variety of forms of difference (MayorgaGallo 2019). This broad conceptualization of diversity, which goes beyond race, sex, and other traits protected by civil rights law, and equates the personal (e.g., personality, interests) with the structural (e.g., racial identity). As such, it maintains and reproduces the racial status quo, including White privilege and dominance.

Diversity as intent focuses on "good intentions" as a way to signal a commitment to ideals like justice and equality. This signaling is often more symbolic or performative by nature, because the emphasis is on portraying a person or institution as one who values diversity, as opposed to actually addressing or challenging structural inequalities (Mayorga-Gallo 2019). Importantly, only the intentions matter, not the results (Smith and Mayorga-Gallo 2017).

The third tenet, diversity as commodity, involves the ways in which non-Whites are treated as objects, not people, and used by Whites to enhance their own position and lives (Smith and Mayorga-Gallo 2017). Under this logic, Whites can tout the benefits that people of color bring to them and their organizations, while overlooking the structural disadvantages that most people of color experience (Smith and Mayorga-Gallo 2017). This diversity as commodity 
mechanism is very similar to the concept of color-blind correctness and highlights comparable connections to color-blind racism: some White Americans draw from color-blindness to help present themselves as knowledgeable about institutional racism and oppression while simultaneously absolving themselves of any complicity in or responsibility for racism (Jayakumar and Adamian 2017). A central feature of diversity as commodity involves perceived benefits: if there is no perceived benefit for Whites or the existing racial status quo, the value of diversity is then challenged (Mayorga-Gallo 2019; Smith and Mayorga-Gallo 2017; Warikoo 2016).

The final tenet of diversity ideology is diversity as liability (Mayorga-Gallo 2019). Wielded as a calculated response to calls for increased diversity, diversity as liability uses ostensibly reasonable language to suggest, for instance, that diversity is incompatible with American ideals like meritocracy (Mayorga-Gallo 2019). This tenet mirrors the color-blind notion of abstract liberalism; for example, that people of color are less competent and recruited unfairly for their race rather than their qualifications and expected contributions (Bonilla-Silva 2018b). Where abstract liberalism would suggest diversity is a disposable value, however, diversity as liability is unique in that it "creates room both for love of diversity and the need to control diverse spaces and people of color for the sake of [White] comfort, fairness, and high standards" (Smith and Mayorga-Gallo 2017: 902).

Diversity ideology allows people (and organizations) to express superficial, symbolic support for diversity, yet simultaneously disavow themselves of any actual responsibility for transforming social structures or perpetuating inequalities. This approach is very similar to colorblind racism, which allows Whites the ability to discuss race without appearing racist by relying on "rational" interpretations of social outcomes (Bonilla-Silva 2018b). Using color-blind racism, 
Whites can oppose practical solutions to existing racial inequality, yet claim their objections are reasonable, and even moral, through principled objection. For example, they might say that people should be rewarded through their own hard work, and not through forced opportunity structures, which is how many people perceive diversity efforts (Berry and Bonilla-Silva 2008). Likewise, through a color-blind approach, one may say that inequalities are driven by things like social class, individual motivation and values, and a fair system of meritocracy, while simultaneously deeming racial discrimination to be unimportant and insignificant because legislation has outlawed it.

Both diversity ideology and color-blind racism are marked by conflicting beliefs, which allow people who live or work in increasingly diverse environments to reconcile American ideals like egalitarianism with persisting racial disparities. The inequality persists, at least in part, because Whites can rationalize their inaction, which ultimately reinforces the status quo and allows them to maintain dominance (Embrick 2011; Mayorga-Gallo 2014; Smith and MayorgaGallo 2017). Diversity ideology and color-blind racism are mutually reinforcing ideologies, and diversity ideology is interlaced with the frames of color-blind racism. Whereas color-blind racism involves implicit and even strategic minimization of the importance of race and racism, some tenets of diversity ideology allow for the direct acknowledgement--and even appreciation-of racial differences, while allowing structural inequality to remain intact (Mayorga-Gallo 2019). As Smith and Mayorga-Gallo (2017:890) put it, "Essentially, diversity ideology highlights race (and other axes of difference) to achieve colorblind ideals."

\section{DATA AND METHODOLOGY}


We use an online survey study with a vignette to explore our guiding research questions. This study is part of a larger research project conducted by [blinded] between 2010-2016 on beliefs about workplace diversity, racial attitudes, and the extent to which organizational diversity interventions may influence workplace decision making and reduce inequality ([blinded] 2017; 2018b). The study includes two parts. In the first part, we asked the participants about their beliefs about organizational diversity using a close-ended question with two response options and a follow-up open ended-question asking the respondent to elaborate on their prior response in their own words. In the second part, we asked the participants to review a vignette involving a Black man being considered for a promotion after being initially overlooked. We then asked them to make a recommendation regarding his promotion. By intentionally utilizing a diverse sample, we go beyond much of the existing research that mainly focuses on White Americans. All participant comments shown are verbatim, aside from minor technical edits for clarity (e.g., spelling).

\section{Sample}

Participants include 226 Stanford alumni and parents of Stanford students, and 85 community college students who participated in the study through the Institute for Research in the Social Sciences at Stanford University. Participants range between 17 - 92 years of age, with an average age of 44. Sixty-four percent are women ${ }^{1}$; 54 percent are White, 3 percent are Black, 6 percent are Latinx, 17 percent are Asian, and 8 percent identify as racially Other $^{2}$ (see Table 1 ). While this sample is broader than a convenience sample of undergraduate students for increased generalizability, it is not an ideal national probability sample. Additionally, because the sample does not include significant numbers of non-White participants, most of our comparative analysis is based on Whites and non-Whites. 


\section{TABLE 1 ABOUT HERE}

\section{Part 1: Diversity Beliefs}

To examine the extent to which respondents believe it is important for organizations to strive for diversity, participants were asked, "Some people believe that diversity is an important goal for organizations, while others believe diversity efforts have gone too far. What is your view?" Participants then indicated their personal beliefs by selecting one of two fixed choices: "diversity is an important goal for organizations" or "diversity efforts have gone too far." In order to better understand beliefs about diversity, participants were then asked to respond to a related open-ended question: "What is the main reason you feel this way [that diversity is an important goal for organizations or that diversity efforts have gone too far]?"

After grouping responses to this question, we focused more specifically on the qualitative responses of the participants who believe that diversity is an important goal for organizations. We took the data through a multiple stage coding process, reading each participant response individually. We first identified broad thematic concepts in responses and refined these into more specific themes by taking the data through numerous coding passes. Three primary themes surfaced as to why diversity is considered important: (1) it enhances outcomes (decision making, serving clients, creativity); (2) there are historical and contemporary problems involving underrepresentation, bias, and discrimination; and (3) demographics are changing, and organizations should reflect that.

\section{Part 2: Workplace Decision Making}

In order to further examine how the participants' beliefs about diversity relate to workplace decisions such as hiring and promotions, participants were given a short vignette about two workers at a fictitious company: Darnell and John. The vignette reads: 
Darnell is a fourth-year associate at Max Corp. When John, a new associate with previous experience was hired, a senior partner asked Darnell to 'show him the ropes' at Max Corp. Darnell, John, and the senior partner would all be working together in the same division. Darnell agreed and felt that this would be a good opportunity to demonstrate his leadership at the company. After a few months, Darnell noticed that John and the partner were getting along very well. The partner praised John's performance, they frequently went out to lunch, and they were always chatting amongst themselves in the partner's office. Darnell also noticed that John was receiving more of the assignments with the most prestigious clients.

A year later, John was recommended for promotion, mainly as a result of his performance on a case with a very prestigious client and a fine recommendation from the partner. Although both employees did promising work and had similar evaluations on record, Darnell was not recommended for promotion. Darnell became concerned due to the fact that, of 39 associates who were promoted this year at Max Corp, only three were members of a racial minority group. Darnell has requested that his situation be reviewed.

While neither employee is explicitly identified racially, clues suggest that Darnell is a racial minority, more specifically a Black man, as Darnell is a Black-sounding name (Holbrook, Fessler, and Navarrete 2016; Levitt and Dubner 2005). Additionally, Darnell expressed concern about the lack of racial minorities receiving promotions at his company, leading him to request a review of his own lack of promotion. ${ }^{3}$ After reading the vignette, participants were asked to recommend one of the candidates for promotion - Darnell or John. The question read: "Only one person in this division can be promoted. At this point, based on your expertise and opinion, what preliminary recommendation do you wish to submit to the committee?" We coded each respondent based on their final recommendation to promote either Darnell (the non-White candidate) or John (the White candidate). We then further analyzed the extent to which patterns discovered in the open-ended responses about the importance of diversity relate to the way individuals respond to the workplace vignette (i.e., deciding whether or not to promote a Black man).

\section{FINDINGS}




\section{Overview}

Most respondents express that diversity is good as a general concept, with 248 of the 311 surveyed (80 percent) reporting that they believe diversity is an important goal for organizations, while 20 percent think diversity efforts have gone too far. Women are more likely than men to believe that diversity in organizations is an important goal: 83 percent of women in the full sample indicated this belief, as compared to only 75 percent of men. With the exception of Asian respondents, racial and ethnic minorities were more supportive of organizational diversity than White respondents. Eighty percent of Latinx respondents, 100 percent of Black respondents, and 81 percent of Other race respondents believe that organizational diversity is an important goal, compared to 73 percent of White respondents and 72 percent of Asian respondents.

After reviewing the vignette, participants were told to only recommend one of the two candidates for promotion: John, a White candidate, or Darnell, a Black candidate. The firm partner recommended John, although both candidates were qualified and there was some indirect evidence of bias and structural barriers. Overall, only about one-third (35 percent) of the 311 participants responded that they would recommend Darnell for the promotion. Women, including White women, were the most likely to recommend the Black man for promotion. For example, 40 percent of White women promoted the Black man, compared to only 10 percent of White men. There were race differences as well. 75 percent of Black women, 67 percent of Black men, 58 percent of Latinas, 13 percent of Latinos, 42 percent of Asian women, 38 percent of Asian men, 43 percent of Other race women, and 40 percent of Other race men recommended Darnell for the promotion.

We next analyzed this promotion decision in relation to the respondents' belief in the importance of diversity. Of the 59 respondents who indicate that diversity efforts have gone too 
far, only 24 percent would recommend Darnell for promotion. This low proportion is unsurprising given their negative orientation towards organizational diversity. Interestingly, however, only 38 percent of those who say that diversity is an important goal would take action to promote the Black man.

In addition to revealing race and gender differences in diversity beliefs and antiracist workplace action, these findings reveal what we are calling a principle-practice gap. This builds on existing research identifying the principle-policy gap to further examine the inconsistency between general support for the principle of diversity (belief that diversity is an important goal) and the actions one is willing to take to actually promote diversity and broaden opportunity (promoting a Black man). In the following section, we analyze the participants' open-ended survey responses to better understand this disconnect between principle and practices, utilizing diversity ideology, which we are the first to contribute to the literature.

Because we are most interested in this principle-practice gap, in the remainder of the analysis, we focus only on the 248 respondents ( 80 percent of the sample) who expressed that diversity in organizations is an important goal. Focusing on these respondents allows us to further examine the beliefs and decision making of those who in principle endorse the value of diversity. The aim is to better understand any gaps that may exist between this principled belief and their ultimate actions in the workplace.

Narratives about Diversity

When answering our focus question ("What is the main reason you feel this way [that diversity is an important goal for organizations or that diversity efforts have gone too far]?"), the 80 percent of participants who agree that diversity is important elaborated with two primary narratives: diversity enhances outcomes, and diversity addresses inequality. A smaller subset 
responded with other explanations, including that diversity is needed based on demographic shifts, personal narratives (often about personal relationships or observations), or some combination of these.

The most common narrative expressed by participants is that diversity is an important goal because it provides some benefit or improves outcomes. This is consistent with the diversity as commodity tenet of diversity ideology. One 26-year-old Asian man put it very succinctly, saying, "Diversity helps with the bottom line." Similarly, a 30-year-old Black man offered, “Diverse viewpoints are critical to an organization's success." Giving a little more detail, a 29year-old White woman explained why she believes diversity efforts are important for organizations: "We need diversity to bring in more creativity and innovative ideas. We also need to better understand our increasingly diverse clientele or consumer, etc." Each of these comments are representative of the beliefs expressed by the majority of participants who see diversity as an important goal for organizations because it enhances outcomes and enriches the business environment.

The second most common narrative entailed respondents who point to existing inequalities to show why diversity is an important goal in organizations. These participants focused more on the need for organizations to do something to address ongoing inequities, typically acknowledging discrimination ("To end discrimination based on race, sex, sexual orientation, etc.” [52-year-old Latino man]) or calling for equal opportunity ("Everyone deserves an equal chance to an opportunity." [37-year-old Other man]). Other participants discussed continued underrepresentation of people of color, exemplified by the comments of a 34-year-old Black woman: "There is still an under representation of minorities in many corporations in the 
U.S. and very few women and minorities in decision making positions. This affects the overall social-economic state of minorities in the U.S. Still the lowest paid and underrepresented."

The remainder of participants did not discuss diversity in terms of its benefits to organizations or in addressing discrimination. Instead, a smaller subset of respondents expressed that diversity is an important goal because organizations should mirror shifting population demographics, without stating specifically that this will enhance outcomes or address inequality. For example, a 47-year-old White woman wrote, "Society is diverse. Organizations should represent that diversity." Finally, a handful of participants relied on personal narratives that did not fit into these primary categories, often referring to non-White family members or other personal experiences as reasons why they think diversity is important. An illustrative example comes from a 49-year-old White woman, who stated, "My husband and daughters are black."

It is also important to note that these emergent themes are not mutually exclusive; in other words, some participant comments overlapped across narratives. For instance, some respondents discussed both the importance of addressing inequality and the benefits of diversity, like this 53-year-old Latina woman: "Besides the fact that it has been proven that the lack of diversity has led to many injustices within many organizations, globalization mandates diversity in order to compete on a global market."

These results also reveal some general patterns in how people respond by race and gender. All groups are most likely to express narratives about the benefits of diversity, but men of color were particularly likely to discuss improved outcomes (71 percent) compared to other demographic groups. Women of color and White women were somewhat more likely to discuss diversity goals as a way to address inequality, compared to men of color and White men. 
Next, we analyze how participants' primary narratives correspond with their decision to promote a Black man (see Table 2). Table 2 includes only participants who believe, in principle, that organizational diversity is an important goal; thus, a lower promotion rate indicates a larger principle-practice gap for individuals who express that particular narrative. For example, the gray row at the top of Table 2 indicates that 51 percent of individuals who believe organizational diversity is important to address inequalities recommend Darnell for promotion, while only 31 percent of those who think diversity is important because it improves outcomes promoted Darnell. Only 36 percent of those who express a combined narrative of inequality and outcomes promote Darnell, which is also substantially less than those who only discuss inequality. Overall, this finding reveals that participants who think diversity is important for addressing inequalities show less of a disconnect between their belief that diversity is important and the action of hiring a Black man. In other words, these individuals have the least pronounced principle-practice gap.

\section{TABLE 2 ABOUT HERE}

These findings do vary some by race and gender. For example, White men who state that diversity is an important goal are very unlikely to recommend the Black man regardless of the narrative they express about why diversity is important. On the other hand, certain women of color, including Black, Latina, and Other race women who think diversity is important will promote the Black man a majority of the time, despite their narrative about why it is important. The Asian women in this study behave more similarly to the White women than the other women of color, and the narrative is more indicative of their behavior. The Asian and White women who believe diversity is important because of inequality have a greater tendency to promote the Black man (56 percent and 59 percent respectively) compared to those who say it is important for the better outcomes it creates ( 28 percent and 38 percent respectively). All of the Black, Latino, and 
Other race men who say diversity is important because of inequality promote Darnell, while only 21 percent of this group who emphasize outcomes are willing to promote Darnell.

A deeper look at the mutually reinforcing structures of diversity ideology and color-blind racism provides more illumination for why this disconnect between principle and practice occurs, and why it is less likely for those who emphasize the need to address inequality. The framework of diversity ideology, which is often laced with color-blind racism, allows people to reconcile American ideals like egalitarianism with ongoing inequalities. Whereas color-blind racism necessitates the minimization or explaining away of race and racism, diversity ideology holds appreciation and recognition of racial difference at its core, and even commodifies it in theory--albeit without expectations of practices that work to improve outcomes for people of color. As such, a 61-year-old White male participant can list multiple benefits of diversity ("Diverse perspectives have been shown to improve problem-solving abilities for teams, organizations, institutions."), yet still decide not to take substantive action that backs up his beliefs or alters the racial status quo.

There is also significant overlap between abstract liberalism (a frame of color-blind racism) and diversity ideology, specifically through the diversity as liability tenet (Smith and Mayorga-Gallo 2017). At the same time as diversity is lauded, it is seen as a threat to American values like meritocracy (and White dominance), similar to abstract liberalism. Put another way, this is a belief that you cannot both hire qualified people and carry out diversity efforts that lead to structural change for people of color in the workplace

This helps explain how several of the participants in our study agreed that diversity is an important goal, yet also expressed implicit or direct opposition to diversity efforts, and further did not act to promote the Black man. For example, one 68-year-old White man provides a 
representative example, referencing the classically color-blind sentiment of "qualifications," stating, "As long as you hire the best people diversity is good." Similarly, a 56-year-old White woman's comments demonstrate how some participants touted the importance of diversity efforts--as long as they didn't go "too far":

"Diversity IS an important goal because the ability of an organization to think broadly and not be stuck in a rut depends upon creativity and different points of view/experience. I am however against profiling such that persons who are underqualified get hired or promoted ahead of more qualified persons simply for the sake of diversity."

Neither of these individuals promoted Darnell, and the woman's commentary is particularly interesting given that the vignette clearly outlines how Darnell is equally qualified to John, his White counterpart, if not more qualified based on tenure in his position and the fact that he was asked to train John. These ostensibly rational, common sense arguments against diversity only serve to signal superficial support for diversity, while maintaining current structures.

\section{DISCUSSION AND CONCLUSION}

Through this project, we sought to answer three main questions: First, to what extent do people believe it is important for organizations to strive for workplace diversity? Second, how do they explain their views regarding why organizational diversity is important? Third, how do these attitudes about workplace diversity influence individual employment decisions? To answer

these questions, we used a survey study with a vignette to assess the connections between beliefs and actions for 311 adults. Our intentional inclusion of a diverse sample moves beyond most extant research on diversity ideology, the bulk of which focuses primarily on White Americans. However, limitations in our sample prevent us from making a more nuanced analysis of race in 
parts of the study. There were relatively few Black, Latino/a, and Other race respondents. This necessitated that we collapse our sample into "White," "Asian," and a combined category of "Black, Latino/a, and Other" race when reporting some of the results. Future research should seek to further investigate differences that may exist among non-Whites through more intentional inclusion of higher numbers of people of color.

Our findings reveal a disconnect between the espoused beliefs about the importance of diversity and corresponding actions to advance diversity, which we identify as a principlepractice gap, an extension of the principle-policy gap (Smith and Mayorga-Gallo 2017). By extending research on the principle-policy gap, we add to existing knowledge by demonstrating how diversity ideology shapes beliefs about workplace diversity. These findings may in turn explain why some people's expressed support for principles like diversity and equality fail to align with actions that create positive change for people of color in the workplace.

Generally, 80 percent of the participants in the full sample endorsed the notion that diversity is an important goal in organizations. However, respondents gave different reasons as to why, such as to improve outcomes, address inequality, or because of shifting demographics. Our findings did reveal some patterns across race and gender. Compared to men of color and White men, women of color and White women were somewhat more likely to say that diversity should be a goal to address inequality. Thus, the different ways in which participants frame their perspective on diversity's importance also sheds light on their ultimate workplace decisions.

White women and people of color who say diversity is important were more likely to promote the Black man than their White counterparts. For White men, it doesn't matter what narratives they express or the reasons they give for why diversity is important; they still do not promote a Black man. As such, they reinforce prevailing White male dominance, particularly in 
leadership positions (e.g., the issue presented in the vignette). These findings are consistent with research showing that White men typically believe company policies are fair and inclusive as a result of formal workplace processes, while White women, due to their awareness of informal discriminatory practices, are less likely to believe equality has been achieved (Mor Barak et al. 1998). Thus, as a result of personal experiences with discrimination or empathy for other women who experience discrimination, women typically have more favorable beliefs about workplace diversity initiatives (Mor Barak et al. 1998). This study suggests that such experiences may engender greater support for diversity efforts designed to promote racial diversity.

White women are much more likely to promote the Black man than White men are, but this corresponds with the narratives they express. Both White women and Asian women who say diversity is important because of inequality are more likely to promote the Black man than those who contend that diversity is important for business outcomes. This could be because Asian and white women who think about diversity improving business outcomes are envisioning other specific types of diversity, such as women for gender diversity or Asians for racial diversity. On the other hand, those thinking about historical or existing inequality may be more likely to also consider the importance of including Black men like Darnell.

The strongest contribution of this project is that our findings connect diversity narratives to outcomes, more specifically whether or not participants would actually promote a Black man. Put another way, the study vignette presented us with an opportunity to see whether participants' beliefs aligned with their actions. Overall, they did not. Existing research helps to explain this, showing that while White American's support of various principles of equality (e.g., integrated schools, interracial marriage) has increased significantly in recent decades, their support of actions and policies that directly address inequality is much lower, and has even decreased in 
some cases (Krysan and Moberg 2016). It appears that actions follow the same patterns for support of policies.

We posit that diversity ideology represents one explanation for the persistent principlepractice gap revealed in this project. Diversity ideology holds that intentions, not outcomes, are most important (Mayorga-Gallo 2019). As such, our participants can have many motivations for expressing support for diversity--because they truly believe in it, or as a way to signal that they are equity-minded or racially-tolerant, or even as a form of "woke" capital (Jayakumar and Adamian 2017) --yet a majority can still fail to back up their principled expressions with concrete action. This line of research on diversity ideology helps us further understand the narratives individuals use to describe the importance of workplace diversity efforts, and taking these findings in a novel direction, how these narratives correspond with their actions--in this case, promoting a Black man.

The nature of ideology may also provide some clues regarding the emergent differences across race, in particular looking at color-blind ideology once again. The various aspects of color-blindness work together to create an almost impermeable ideological structure, like a sturdy house. Research suggests that people of color, however, are indirectly impacted by colorblindness and use it in much more nuanced, contradictory ways than their White counterparts (Cox 2021). Because of this nuance, there are more gaps in the walls of the house that result in a much less stable (ideological) structure--in other words, people of color may express views in line with meritocracy, yet easily point to discriminatory practices and other structural impediments to their upward mobility (Cox 2021). Diversity ideology may work in similar ways for people of color, where they are indirectly impacted such that they frame some of their beliefs 
about diversity overall through the language of diversity ideology, yet are more likely to take direct actions to counter structural problems.

So why does our data consistently show White respondents as least likely to demonstrate a connection between their espoused beliefs and commensurate actions? Diversity ideology is a form of logic that perpetuates and maintains White dominance by allowing for a minor, fairly abstract recognition of structural inequalities while resulting in no actual, substantive changes for people of color (Mayorga-Gallo 2014, 2019; Smith and Mayorga-Gallo 2017). In other words, people can acknowledge diversity and racial difference, yet deny or ignore systemic oppression and racial injustice. This disconnect is possibly best seen through the diversity as liability tenet of diversity ideology. In our study, participants who discussed the benefits of diversity in the workplace yet simultaneously stated that diversity can go "too far," often by hiring "unqualified people," illustrated the ways in which diversity ideology maintains White dominance. The commentary of these participants--most often White men and women--highlight a perceived trade-off between diversity and meritocracy. Here the overlap with color-blind ideology is also informative.

Research by Berry and Bonilla-Silva (2008) demonstrates that through the abstract liberalism frame of color-blindness, White Americans often hold a philosophy of diversity or qualifications that can be mobilized in multiple ways to support individual interests. This mindset allows support of diversity in the abstract, yet impedes action because it relies on the underlying assumption that candidates that offer diversity somehow lack ample qualifications. This frame of thinking is significant because it often serves to mask prejudiced ideas that Black people and other people of color are assumed to be inherently less qualified. 
Our findings further support the prevalence of this philosophy. The arguments our White respondents used imply (or assert) that efforts towards diverse hiring practices are fundamentally at odds with hiring qualified people. Respondents appear to believe that it is impossible to hire someone who is both highly qualified and who will add diversity to an organization. This is important because such logic not only relegates minorities to the label of unqualified, but also works to maintain the racial status quo in which Whites continue to be the dominant group in the workforce, all but ensuring their concentration in positions of power.

The implications of our findings are particularly important for understanding how White Americans approach issues of diversity in real organizational contexts, highlighting the disconnect between beliefs and actions. In the case of our study, White participants who claim diversity is important had the opportunity to enact these beliefs and thus reduce the impact of structural racism in the workplace, yet the majority of them continued to uphold a racial status quo that maintains White privilege and dominance.

Based on existing research that corresponds with our study results, White participants demonstrate such a stark disconnect between their beliefs and actions in large part to signal their support of equality and minor, abstract recognition of structural inequality (Mayorga-Gallo 2017). This superficial recognition does not require supportive actions, however; thus, White people (and others, to a lesser extent) can tout the importance of diversity in workplaces yet do nothing to change workplace structures that perpetuate White advantage. This pattern may further explain why organizations seem to be valuing diversity on the surface, yet so many of the efforts have had little effect on workplace outcomes for marginalized groups (Edelman 2016; Kalev and Dobbin 2006). 
In this way "wokeness" serves as a form of symbolic capital, highlighting another potential reason why some of the White participants in our study say one thing but do another: acknowledging the existence of racism, particularly structural forms that impact spaces like the workplace, has become somewhat of a "trendy" thing to do. We have observed many examples of this in light of the increased spotlight on BLM (Parker, Horowitz, and Anderson 2020; Wortham 2020). Even a cursory glance at recent media coverage supports this idea, from stories detailing how best to create diverse workplaces (Pedulla 2020; Robert 2020) to those still making the business case for diversity (Schindler 2019). Combined with color-blindness, this trendiness allows Whites in particular to reap the benefits of superficial recognition of racism and White advantage-they signal "wokeness" but can avoid any real responsibility for enacting changes that might result in a change in the status quo. Diversity ideology serves as the ideological mechanism that allows many of the individuals in our study to express support for the principles of diversity and diversity efforts while simultaneously not taking any real action to address existing inequalities in the workplace. Although this is a completely subconscious process for some, while part of a conscious effort for others, the end result is still the same: Whites maintain advantage, and people of color maintain disadvantage-the racial hierarchy is reinforced, and the (racial) wheel keeps turning. 


\section{NOTES}

1. Nineteen participants did not indicate gender.

2. Thirty-three participants did not indicate race.

3. We decided not to use the most stereotypically Black names such as "Jamal" or "Tyrone" which could cause suspicion that we are measuring racial discrimination and lead to demand effects such as social desirability bias. 
Table 1. Sample Characteristics, Diversity Beliefs, and Workplace Decision

\begin{tabular}{|lcc|}
\hline \multicolumn{2}{|c|}{$\begin{array}{c}\text { N = 311 Participants* } \\
\text { percent of Total Sample }\end{array}$} \\
\hline Gender & 200 & \\
Women & 92 & $64.3 \%$ \\
Men & & $29.6 \%$ \\
Race/ethnicity & 54 & \\
Asian & 11 & $17.4 \%$ \\
Black & 20 & $3.5 \%$ \\
Latino & 26 & $6.4 \%$ \\
Other & 167 & $8.4 \%$ \\
White & 111 & $53.7 \%$ \\
Total non-white & & $35.7 \%$ \\
Diversity Beliefs & & \\
Diversity is an important goal for & 248 & \\
organizations & & \\
Workplace Decision & 109 & $35.0 \%$ \\
Recommend Promoting Black Man &
\end{tabular}

*Nineteen participants did not indicate gender, 33 participants did not indicate race, and 3 participants did not indicate whether they believe diversity has gone too far or diversity is an important goal for organizations. 
Table 2. Promotion Decisions of Respondents who Believe Diversity is an Important Goal By Narrative Explaining Why Diversity is Important and Race/Gender $(\mathrm{n}=248)$

\begin{tabular}{|c|c|c|c|c|c|}
\hline & $\begin{array}{c}\text { Inequality } \\
n=76\end{array}$ & $\begin{array}{c}\text { Improves } \\
\text { Outcomes } \\
\mathbf{n}=\mathbf{1 2 1}\end{array}$ & $\begin{array}{c}\text { Inequality + } \\
\text { Outcomes } \\
n=22\end{array}$ & $\begin{array}{c}\text { Demographic } \\
\text { /Other } \\
\mathbf{n}=\mathbf{2 9}\end{array}$ & $\begin{array}{l}\text { TOTAL } \\
\text { who } \\
\text { Promote } \\
\text { BM } \\
\end{array}$ \\
\hline $\begin{array}{l}\text { TOTAL percent within } \\
\text { narrative who promote } \\
\text { Black Man }\end{array}$ & $\begin{array}{c}51 \% \\
(39 / 76)\end{array}$ & $\begin{array}{c}31 \% \\
(37 / 121)\end{array}$ & $\begin{array}{c}36 \% \\
(8 / 22)\end{array}$ & $\begin{array}{c}34 \% \\
(10 / 29)\end{array}$ & $\begin{array}{c}38 \% \\
(94 / 248)\end{array}$ \\
\hline $\begin{array}{l}\text { Percent of White } \\
\text { Women within } \\
\text { narrative who promote } \\
\text { BM }\end{array}$ & $\begin{array}{c}59 \% \\
(17 / 29)\end{array}$ & $\begin{array}{c}38 \% \\
(16 / 42)\end{array}$ & $\begin{array}{c}40 \% \\
(4 / 10)\end{array}$ & $\begin{array}{l}25 \% \\
(2 / 8)\end{array}$ & $\begin{array}{c}44 \% \\
(39 / 89)\end{array}$ \\
\hline $\begin{array}{l}\text { Percent of Asian } \\
\text { Women within } \\
\text { narrative who promote } \\
\text { BM }\end{array}$ & $\begin{array}{l}56 \% \\
(5 / 9)\end{array}$ & $\begin{array}{c}28 \% \\
(5 / 18)\end{array}$ & $\begin{array}{c}0 \% \\
(0 / 1)\end{array}$ & $\begin{array}{c}0 \% \\
(0 / 1)\end{array}$ & $\begin{array}{c}34 \% \\
(10 / 29)\end{array}$ \\
\hline $\begin{array}{l}\text { Percent of Black, } \\
\text { Latina, and Other } \\
\text { Women within } \\
\text { narrative who promote } \\
\text { BM }\end{array}$ & $\begin{array}{c}62 \% \\
(8 / 13)\end{array}$ & $\begin{array}{c}57 \% \\
(8 / 14)\end{array}$ & $\begin{array}{l}67 \% \\
(2 / 3)\end{array}$ & N/A & $\begin{array}{c}60 \% \\
(18 / 30)\end{array}$ \\
\hline $\begin{array}{l}\text { Percent of White Men } \\
\text { within narrative who } \\
\text { promote BM }\end{array}$ & $\begin{array}{l}11 \% \\
(1 / 9)\end{array}$ & $\begin{array}{c}5 \% \\
(1 / 19)\end{array}$ & $\begin{array}{c}0 \% \\
(0 / 4)\end{array}$ & $\begin{array}{c}0 \% \\
(0 / 1)\end{array}$ & $\begin{array}{c}6 \% \\
(2 / 33)\end{array}$ \\
\hline $\begin{array}{l}\text { Percent of Asian Men } \\
\text { within narrative who } \\
\text { promote BM }\end{array}$ & $\begin{array}{l}50 \% \\
(2 / 4)\end{array}$ & $\begin{array}{l}50 \% \\
(3 / 6)\end{array}$ & N/A & N/A & $\begin{array}{c}50 \% \\
(5 / 10)\end{array}$ \\
\hline $\begin{array}{l}\text { Percent of Black, } \\
\text { Latina, and Other Men } \\
\text { within narrative who } \\
\text { promote BM }\end{array}$ & $\begin{array}{c}100 \% \\
(3 / 3)\end{array}$ & $\begin{array}{c}21 \% \\
(3 / 14)\end{array}$ & N/A & $\begin{array}{c}100 \% \\
(1 / 1)\end{array}$ & $\begin{array}{l}33 \% \\
(6 / 18)\end{array}$ \\
\hline
\end{tabular}

*39 participants who believe diversity is an important goal did not report race and/or gender, thus are not included in race/gender breakout 


\section{REFERENCES}

Agan, Amanda Y. and Sonja B. Starr. 2016. "Ban the Box, Criminal Records, and Statistical Discrimination: A Field Experiment." University of Michigan Law and Economics Research Paper 16-012.

Bell, Joyce and Douglas Hartmann. 2007. "Diversity in Everyday Discourse: The Cultural Ambiguities and Consequences of 'Happy Talk." American Sociological Review 72:895914.

Berrey, Ellen. 2015. The Enigma of Diversity: The Language of Race and the Limits of Social Justice. University of Chicago Press.

Berry, Brent and Eduardo Bonilla-Silva. 2008. “"They Should Hire the One With the Best Score': White Sensitivity To Qualification Differences In Affirmative Action Hiring Decisions." Ethnic and Racial Studies 31(2):215-242.

Bertrand, Marianne and Sendhil Mullainathan. 2004. "Are Emily and Greg More Employable Than Lakisha and Jamal? A Field Experiment on Labor Market Discrimination.” American Economic Review 94(4):991-1013.

Bonilla-Silva, Eduardo. 2018a. “'Racists,' 'Class Anxieties,' Hegemonic Racism, and Democracy in Trump's America." Social Currents 6(1):14-31.

Bonilla-Silva, Eduardo. 2018b. Racism without Racists: Color-Blind Racism and the Persistence of Racial Inequality in America. 5th ed. Oxford: Rowman \& Littlefield Publishers, Inc.

Borrell, Luisa N., David R. Jacobs Jr., David R. Williams, Mark J. Pletcher, Thomas K. Houston, and Catarina I. Kiefe. 2007. "Self-reported Racial Discrimination and Substance Use in the Coronary Artery Risk Development in Adults.” American Journal of Epidemiology 166(9):1068-79. 
Boston Consulting Group. 2019. "The Most Innovative Companies 2019.” Retrieved January 24, 2020 (https://www.bcg.com/publications/collections/most-innovative-companies-2019artificial-intelligence-platforms-ecosystems.aspx).

Cox, Jonathan M. 2021. "When Color-conscious Meets Color-blind: Millennials of Color and Color-blind Racism.” Sociological Inquiry. Online first February 3, 2021.

Dobbin, Frank. 2009. Inventing Equal Opportunity. Princeton, NJ: Princeton University Press.

Dover, Tessa L., Brenda Major and Cheryl R. Kaiser. 2016. "Members of High-Status Groups Are Threatened by Pro-Diversity Organizational Messages.” Journal of Experimental Social Psychology 62(1):58-67.

Edelman, Lauren B. 2016. Working Law: Courts, Corporations, and Symbolic Civil Rights. Chicago, IL: University of Chicago Press.

Edelman, Lauren B., Sally R. Fuller and Iona Mara-Drita. 2001. "Diversity Rhetoric and the Managerialization of Law.” American Journal of Sociology 106(6):1589-1641.

Embrick, David G. 2011. "The Diversity Ideology in the Business World: A New Oppression for a New Age." Critical Sociology 37(5):541-556.

Harmon, Amy and Audra D. S. Burch. 2020. "White Americans Say They Are Waking Up to Racism. What Will It Add Up To?” New York Times, June 22. Retrieved August 19, 2020 (https://www.nytimes.com/2020/06/22/us/racism-white-americans.html).

Holbrook, Colin, Daniel M. T. Fessler and Carlos David Navarrete. 2016. "Looming Large in Others' Eyes: Racial Stereotypes Illuminate Dual Adaptations for Representing Threat Versus Prestige as Physical Size." Evolution and Human Behavior 37(1):67-78.

Hunt, Matthew O. 2007. "African-American, Hispanic, and White Beliefs About Black/White Inequality, 1977-2004.” American Sociological Review 72:390-415. 
Jayakumar, Uma M. and Annie S. Adamian. 2017. "The Fifth Frame of Colorblind Ideology:

Maintaining the Comforts of Colorblindness in the Context of White Fragility." Sociological Perspectives 60(5):912-936.

Kaiser, Cheryl R., Brenda Major, Ines Jurcevic, Tessa L. Dover, Laura M. Brady, and Jenessa R. Shapiro. 2013. "Presumed Fair: Ironic Effects of Organizational Diversity Structures." Journal of Personality and Social Psychology 104(3):504-519.

Kalev, Alexandra, Frank Dobbin, and Erin Kelly. 2006. "Best Practices or Best Guesses? Assessing the Efficacy of Corporate Affirmative Action and Diversity Policies." American Sociological Review 71(4):589-617.

Kang, Sonia K., Katherine A. DeCelles, András Tilcsik and Sora Jun. 2016. "Whitened Résumés: Race and Self-Presentation in the Labor Market." Administrative Science Quarterly 61(3):469-502.

Kossek, Ellen E. and Susan C. Zonia. 1993. "Assessing diversity climate: A field study of reactions to employer efforts to promote diversity." Journal of Organizational Behavior 14(1):61-81.

Krysan, Maria and Sarah Moberg. 2016. "Trends in Racial Attitudes: A Portrait of African American and White Racial Attitudes." University of Illinois Institute of Government and Public Affairs. Retrieved January 24, 2020 (http://igpa.uillinois.edu/programs/racialattitudes).

Levitt, Steven D. and Stephen J. Dubner (2005). Freakonomics: A Rogue Economist Explores the Hidden Side of Everything. New York: William Morrow \& Co.

Mayorga-Gallo, Sarah. 2019. "The White-Centering Logic of Diversity Ideology.” American Behavioral Scientist 63(13):1789-1809. 
Mayorga-Gallo, Sarah. 2014. Behind the White Picket Fence: Power and Privilege in a Multiethnic Neighborhood. Chapel Hill, NC: The University of North Carolina Press. Mayrl, Damon and Aliya Saperstein. 2013. "When White People Report Racial Discrimination: The Role of Region, Religion, and Politics." Social Science Research 42(3):742-54. Miller, Carol and Cheryl Kaiser. 2001. "A Theoretical Perspective on Coping with Stigma." Journal of Social Issues 57(1):73-92.

Mor Barak, MichAl E, David A. Cherin and Sherry Berkman. 1998. "Organizational and Personal Dimensions in Diversity Climate: Ethnic and Gender Differences in Employee Perceptions.” The Journal of Applied Behavioral Science 34(1): 82-104.

Neville, Helen A., Germine H. Awad, James Brooks, Michelle P. Flores and Jamie Bluemel. 2013. "Color-Blind Racial Ideology Theory, Training, and Measurement Implications in Psychology." American Psychologist 68(6):455-66.

Norton, Michael and Samuel Sommers. 2011. "Whites See Racism as a Zero-Sum Game That They Are Now Losing." Perspectives on Psychological Science 6(3):215-218.

Pager, Devah. 2003. “The Mark of a Criminal Record.” American Journal of Sociology 108(5):937-975.

Pager, Devah and Hana Shepherd. 2008. "The Sociology of Discrimination: Racial Discrimination in Employment, Housing, Credit, and Consumer Markets.” Annual Review of Sociology 34:181-209.

Pager, Devah, Bruce Western and Bart Bonikowski. 2009. "Discrimination in a Low-Wage Labor Market: A Field Experiment.” American Sociological Review 74(5):777-799. Parker, Kim, Juliana M. Horowitz, and Monica Anderson. 2020. “Amid Protests, Majorities Across Racial and Ethnic Groups Express Support for the Black Lives Matter 
Movement." Pew Research Center. Retrieved August 19, 2020

(https://www.pewsocialtrends.org/2020/06/12/amid-protests-majorities-across-racial-andethnic-groups-express-support-for-the-black-lives-matter-movement/).

Pedulla, David. 2020. "Diversity and Inclusion Efforts that Really Work." Harvard Business Review. Retrieved August 19, 2020 (https://hbr.org/2020/05/diversity-and-inclusionefforts-that-really-work).

Reeves, Arin. 2013. "Yellow Papers Series 2014-0404, Written in Black \& White: Exploring Confirmation Bias in Racialized Perceptions of Writing Skills.” Nextions. Retrieved January 24, 2020 (http://www.nextions.com/wp-content/files_mf /14151940752014040114WritteninBlackandWhiteYPS.pdf).

Robert, Yola. 2020. “4 Ways To Actually Create Diversity And Inclusion In The Workplace.” Forbes. Retrieved August 19, 2020 (https://www.forbes.com/sites/yolarobert1/2020/06/11/4-ways-to-actually-creatediversity-and-inclusion-in-the-workplace/\#56c8fb7d3fcd).

Sears, David O. and P. J. Henry. 2005. “Over Thirty Years Later: A Contemporary Look at Symbolic Racism.” In M. P. Zanna (Ed.), Advances in experimental social psychology, 37: $95-150$.

Schindler, Janine. 2019. "The Benefits of Cultural Diversity in the Workplace." Forbes. Retrieved August 19, 2020 (https://www.forbes.com/sites/forbescoachescouncil/2019/09/13/the-benefits-of-culturaldiversity-in-the-workplace/\#7ed8354171c0). 
Smith, Candis W. and Sarah Mayorga-Gallo. 2017. "The New Principle-policy Gap: How Diversity Ideology Subverts Diversity Initiatives." Sociological Perspectives 60(5):889911.

Soni, Vidu. 2000. “A Twenty-First Century Reception for Diversity in the Public Sector: A Case Study.” Public Administration Review 60(5):395-408

Stainback, K. and Donald Tomaskovic-Devey. 2012. Documenting Desegregation: Racial and Gender Segregation in Private Sector Employment Since the Civil Rights Act. New York: Russell Sage Foundation.

Taylor, Andrew and Toby Parcel. 2019. "Proximity and the Principle-Policy Gap in White Racial Attitudes: Insight from Views of Student Assignment Policies in Wake County, North Carolina.” Social Science Research 78:95-103.

Warikoo, Natasha K. 2016. The Diversity Bargain and Other Dilemmas of Race, Admissions, and Meritocracy at Elite Universities. Chicago, IL: University of Chicago Press.

Williams, Jamillah B. 2018a. "Does Social Justice Sell?: Examining Instrumental vs. Moral Rationales for Diversity." Academy of Management Proceedings.

Williams, Jamillah B. 2018b. "Accountability as a Debiasing Strategy: Testing the Effect of Racial Diversity in Employment Committees.” 103 Iowa Law Review 1593-1638.

Williams, Jamillah B. 2017. Breaking Down Bias: Legal Mandates vs. Corporate Interests, 92 Washington Law Review 1473-1513. 